\title{
Mining
}

http://dx.doi.org/10.1590/0370-44672014690073

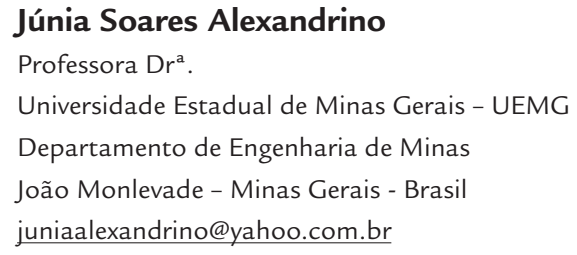

\section{Gilmara Mendonça Lopes}

$\mathrm{Dr}^{\mathrm{a}}$., Analista Operacional

Vale (Mina de Brucutu)

São Gonçalo do Rio Abaixo - Minas Gerais - Brasil gil1203@gmail.com

\section{Otávia Martins Silva Rodrigues \\ Professora Dra . \\ Universidade Federal de Ouro Preto - UFOP \\ Escola de Minas \\ Departamento de Engenharia de Minas \\ Ouro Preto - Minas Gerais - Brasil \\ otaviarodrigues@demin.ufop.br}

\section{Introduction}

The liberation of hematite in the currently available iron ores requires fine grinding. The aggregation between hematite and gangue particles severely impairs the selectivity of concentration via froth flotation or magnetic separation. The use of dispersants in laboratory scale investigations related to iron ores has been reported in the technical literature.

Ferreira (2002) investigated the aggregation/dispersion of iron ore slimes, with emphasis on interfacial phenomena, in the presence and absence of chemical reagents such as metallic cations, cationic and anionic flocculants, and dispersants. The rheological behavior of the pulps was correlated with the dispersion degree and the surface charge of particles.

\section{Dispersion degree and zeta potential of hematite}

\begin{abstract}
The dispersion degree of the mineral particles in the pulp is especially relevant regarding the performance of the cationic reverse flotation of iron ores. The gangue minerals should remain dispersed while hematite particles should be selectively flocculated. The present study addressed determinations of dispersion degree and zeta potential of hematite in the presence of different dispersants, classified as organic polymeric (natural and synthetic), organic monomeric, and inorganic. Special attention was paid to results achieved at $\mathrm{pH} 10$, used in plant practice. For natural organic polymers, correlation was observed between the dispersion degree and the increase in the negative value of zeta potential. Some synthetic organic polymers enhance the dispersion of hematite particles despite not affecting significantly the zeta potential. Sodium silicates, irrespectively of the $\mathrm{SiO}_{2} / \mathrm{Na}_{2} \mathrm{O}$ ratio, at $\mathrm{pH} 10$, did not impact significantly either the dispersion degree or the zeta potential.
\end{abstract}

Keywords: dispersion degree, zeta potential, dispersants, hematite.
Vieira and Peres (2013) reported the results of an investigation addressing the effects of the slurry's rheological behavior and the state of aggregation and dispersion on wet ultrafine grinding of an iron ore concentrate. Regrinding tests were conducted under different conditions of dispersion $(\mathrm{pH} 7.3,8.5$ and 10.0). The increase of $\mathrm{pH}$ from 7.3 to 10.0 increased the slurry dispersion degree, providing lower values of yield stress and apparent viscosity, and a reduction in specific energy consumption of $17.4 \%$. So, sodium hydroxide, added at previous processing steps, has acted as a grinding aid. On the other hand, the addition of $300 \mathrm{~g} / \mathrm{t}$ of lime caused an increase of $27 \%$ in the specific energy consumption, with a significant increase in yield stress and consistency index of the fluid, especially for the condition 18 $\mathrm{kWh} / \mathrm{t}$.

Lima et al. (2012) investigated the effect of slimes on the flotation performance of eight different types of iron ores. The mineralogy of the slimes defines the extent of their harmful effect. The flotation performance may be unaffected by the presence of $30 \%$ slimes, while for another ore type, the presence of an amount as low as $1 \%$ of slimes significantly impairs the process. Similar results were achieved by Marques (2012). Slimes from the ore itself had a severe harmful effect on the flotation performance, while slimes from other sources, even with high goethite contents, did not have any significant impact. The use of dispersant and higher collector dosages inhibited the harmful effect of slimes. 
Carlson (2010) reviewed the electrokinetic properties of iron oxides stressing the effect of zeta potential on aggregation/dispersion of the particles in the pulp. Operations such as filtration, thickening, sedimentation, and mag-

al. (2012) investigated the interaction between sodium silicate and quartz. Strong interaction was observed in the $\mathrm{pH}$ range 5 to 8 . Above $\mathrm{pH} 10$, the interaction was negligible.

The enhanced performance

\section{Experiment}

The pure compact hematite sample from Casa de Pedra mine was supplied by CSN.

The dispersants used in dispersion degree and zeta potential determinations were: dextrin $\left(\right.$ Cargil $\left.^{\circledR}\right)$, FloatanM3 (tannin, UNITAN S.A.I.C.A. $\left.{ }^{\circledR}\right)$; citric acid $\left(\right.$ Cargil $\left.^{\circledR}\right)$, sodium silicate $\mathrm{C} 112 \mathrm{SiO}_{2} /$ $\mathrm{Na}_{2} \mathrm{O}=1.98$ to 2.00 (Diaton $^{\circledR}$ ), sodium silicate $\mathrm{R} 2252 \mathrm{SiO}_{2} / \mathrm{Na}_{2} \mathrm{O}=2.15$ to 2.40 (Diaton ${ }^{\circledR}$ ); sodium silicate $\mathrm{R} 3342 \mathrm{SiO}_{2} /$ $\mathrm{Na}_{2} \mathrm{O}=3.30$ to 3.45 (Diaton ${ }^{\circledR}$ ); Dismulgan V3377 (Clariant $^{\circledR}$ ); Dispersogen LFS (polyarylalkylphenol polyethylene glycol, Clariant $^{\circledR}$ ); Polymax T10 (Huntsman ${ }^{\circledR}$ ); netic separation were addressed. In the magnetic concentration of iron ores the entrapment of silica bearing particles in the aggregates contaminates the concentrate. Selective flocculation is a desliming operation used in the Tilden concentra-

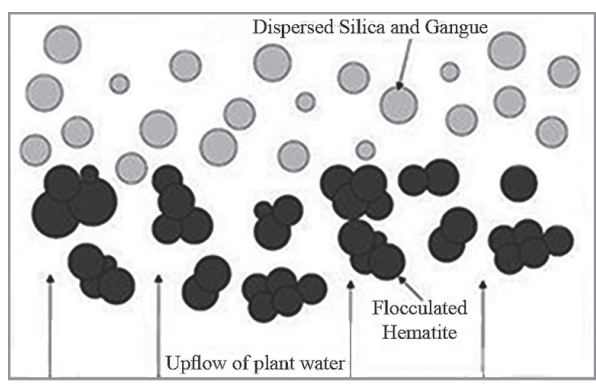

of the reverse cationic flotation of iron ores requires the dispersion of gangue particles, and the selective flocculation of iron oxide particles is desirable. The motivation for the study was to understand the effect tor. The fine particles of minerals bearing silica and other contaminants are kept dispersed and are removed by the upwards water flow. Hematite particles are selectively flocculated, as illustrated in Figure 1.
Figure 1

Desliming via selective flocculation.

of dispersants belonging to different chemical classes, such as organic polymeric (natural and synthetic), organic monomeric, and inorganic, on the dispersion degree and the zeta potential of hematite.
Dispersol 589 (polyacrylate, Clariant ${ }^{\circledR}$ ); Depramin 158 CMC (Akzo Nobel ${ }^{\circledR}$ ). The pure corn starch (Maizena $\left.{ }^{\circledR}\right)$ acts as an iron oxide depressant with selective flocculation action towards hematite with respect to quartz. Its action was compared with that of the dispersants used in the experiments.

Dispersants concentrations of 4 $\mathrm{mg} / \mathrm{L}$ and $14 \mathrm{mg} / \mathrm{L}$ were used in the determinations of the degree of dispersion. An intermediate level of $10 \mathrm{mg} / \mathrm{L}$ was selected for zeta potential determinations. Special attention was paid to the results achieved at $\mathrm{pH} 10$, considering that in the plant practice of cationic reverse flotation of iron ores the $\mathrm{pH}$ is set in the range between 10.0 and 10.4 .

Dispersion degrees were determined in replicated experiments performed in the sedimentation tube described by Galéry (1985).

Zeta potential microelectrophoretical determinations were done in a zetameter apparatus model ZM3-D-G, Zeta Meter systems 3.0+, using video direct images, Zeta Meter, Inc. USA. KCl solution was used as supporting electrolyte. The hematite sample was comminuted to the size range $<10 \mu \mathrm{m}$.

\section{Results and discussion}

Results of dispersion degree and zeta potential determinations in the presence of pure corn starch are illustrated in Figure 2

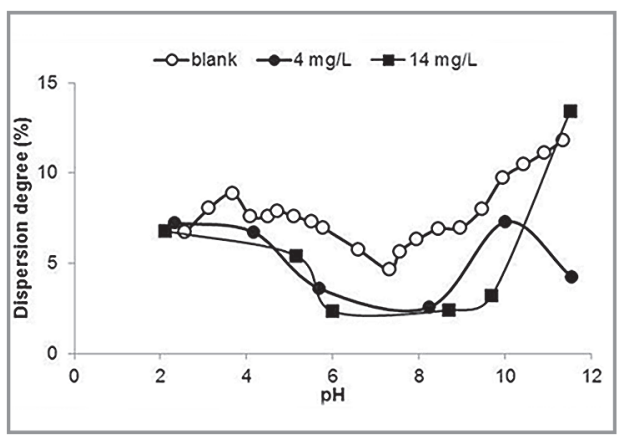

As expected, the pure corn starch at the concentration of $14 \mathrm{mg} / \mathrm{L}$ acted as a flocculant, significantly reducing the hematite dispersion degree at $\mathrm{pH} 10$. For

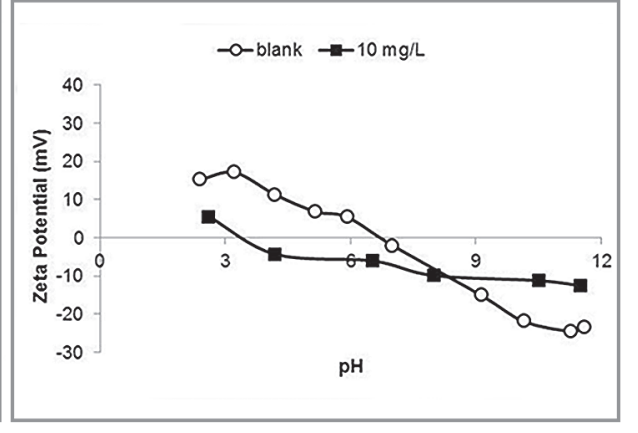

more alkaline conditions, the flocculating action ceased, probably due to the coiling of the starch molecules. The isoelectric point, IEP, was shifted from $\mathrm{pH} 6.7$ in the
Figure 2

Dispersion degree (left) and zeta potential (right) of hematite in the presence of pure corn starch.

blank determination to 3.4 in the presence of starch

Results of dispersion degree and zeta potential determinations in the presence of 
dextrin are illustrated in Figure 3.

Figure 3

Dispersion degree (left) and zeta potential (right)

of hematite in the presence of dextrin.

Dextrin is a modified starch presenting a much lower polymerization degree of the $\alpha-\mathrm{D}$ glucose monomer resulting in a polymer with atomic mass unit value

Figure 4

Dispersion degree (left) and zeta potential (right) of hematite in the presence of FloatanM3.

The presence of tannin clearly increased the dispersion degree. It is difficult to explain the aspect of the curves for the two concentrations used in the experiments, but the

Figure 5

Dispersion degree (left) and zeta potential (right)

of hematite in the presence of citric acid.

At $\mathrm{pH}$ 10, citric acid enhanced the dispersion of hematite, the higher concentration being more effective. The zeta potential was negative in the

Figure 6

Dispersion degree (left) and zeta potential (right) of hematite in the presence of sodium silicate C -112 .

Sodium silicate C- $112\left(\mathrm{SiO}_{2} / \mathrm{Na}_{2} \mathrm{O}\right.$ ratio 1.98-2.00) did not significantly affect the dispersion degree, except for the
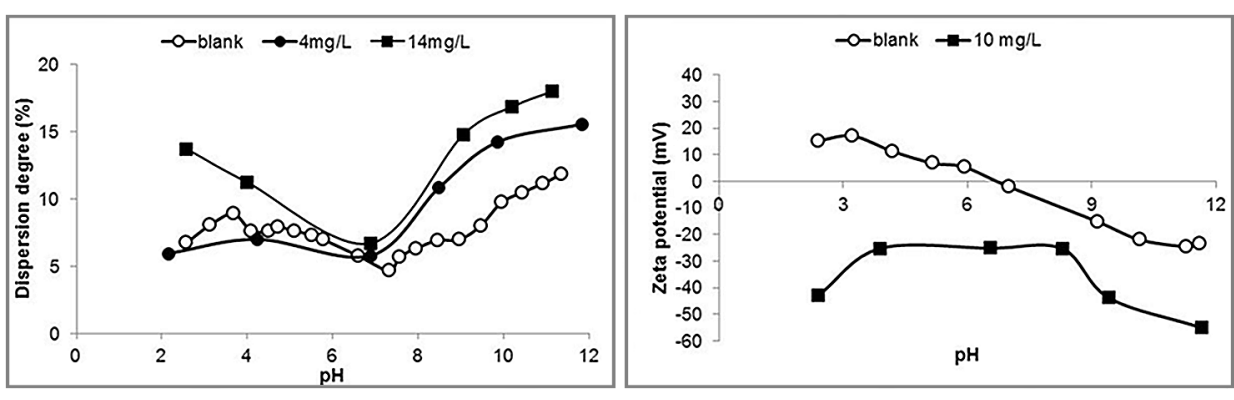

lower than 10,000 which acts as dispersant. The presence of dextrin rendered the zeta potential less negative in the alkaline $\mathrm{pH}$ range and no IEP was observed.

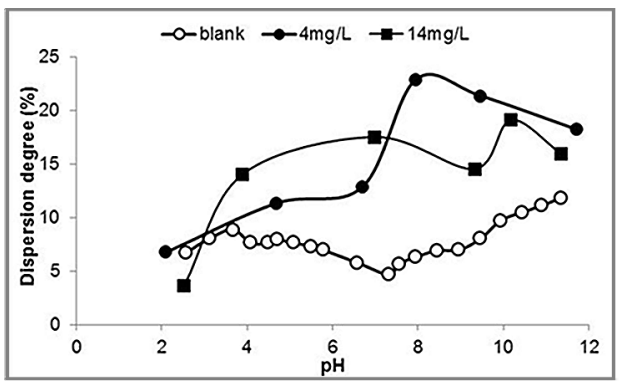

relevant point is that the dispersion degree at $\mathrm{pH} 10$ is similar for both concentrations. Again the dispersant rendered the zeta potential less negative in the alkaline $\mathrm{pH}$ range and no

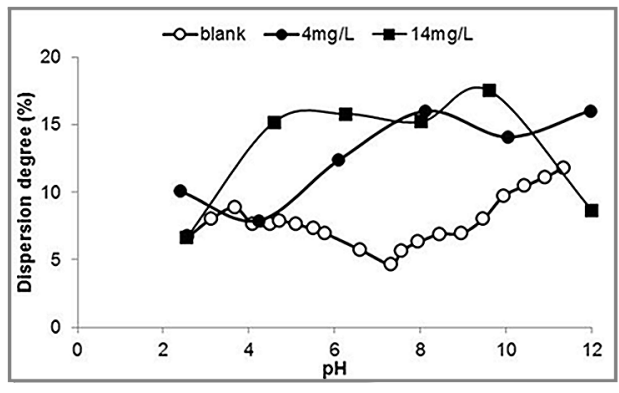

full $\mathrm{pH}$ range investigated, but at $\mathrm{pH}$ 10 the zeta potential was unaffected by the presence of citric acid.

Results of dispersion degree and

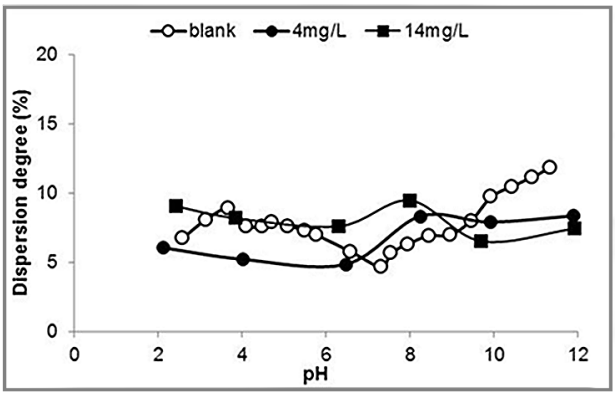

negative effect in the strongly alkaline range. The zeta potential was rendered more negative in the full $\mathrm{pH}$ range, but
Results of dispersion degree and zeta potential determinations in the presence of the tannin FloatanM3 are illustrated in Figure 4.

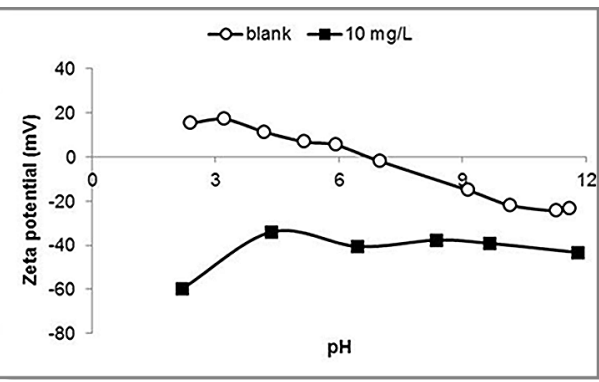

IEP was observed.

Results of dispersion degree and zeta potential determinations in the presence of citric acid are illustrated in Figure 5.

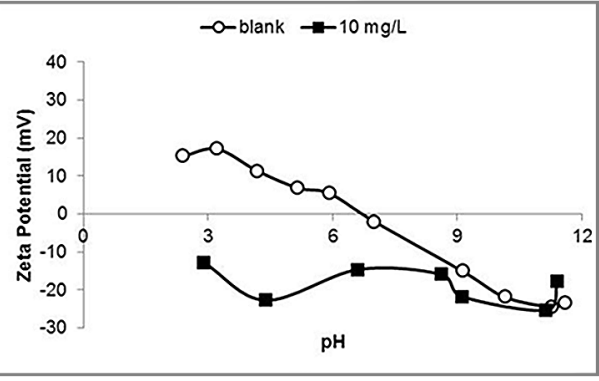

zeta potential determinations in the presence of sodium silicate C-112 are illustrated in Figure 6.



the difference was not significant at $\mathrm{pH} 10$.

Results of dispersion degree and zeta potential determinations in the presence 
of sodium silicate R-2252 are illustrated in Figure 7.

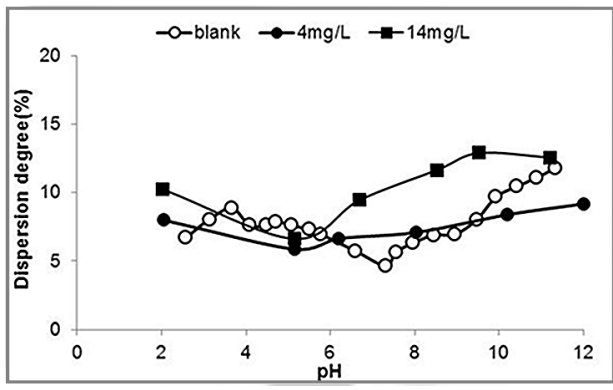

Dosed at the concentration 14 $\mathrm{mg} / \mathrm{L}$, sodium silicate $\mathrm{R}-2252\left(\mathrm{SiO}_{2} /\right.$ $\mathrm{Na}_{2} \mathrm{O}$ ratio 2.15-2.40) increased the dispersion degree and shifted the zeta

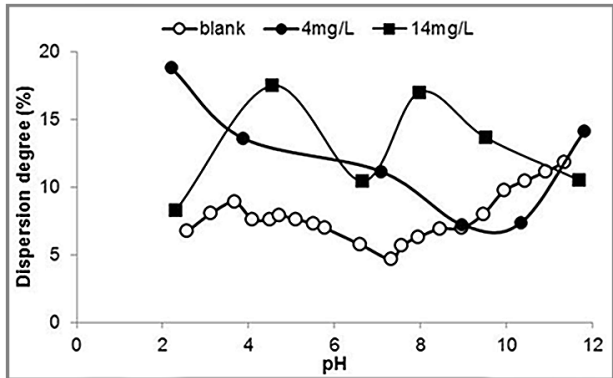

It is difficult to explain the aspect of the dispersion degree curve for the concentration $14 \mathrm{mg} / \mathrm{L}$ of sodium silicate R-3342 $\left(\mathrm{SiO}_{2} / \mathrm{Na}_{2} \mathrm{O}\right.$ ratio 3.30-3.45), nevertheless

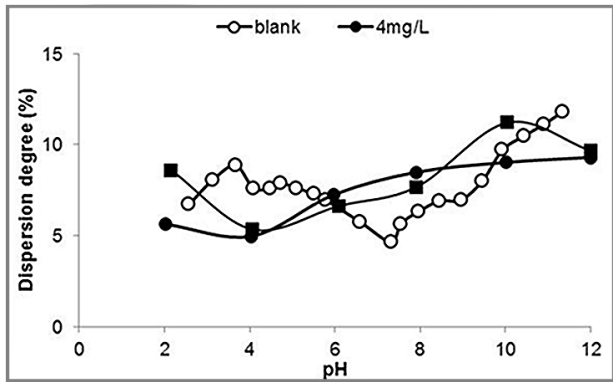

At pH 10 Dismulgan V3377 does not significantly affect either the dispersion degree or the zeta

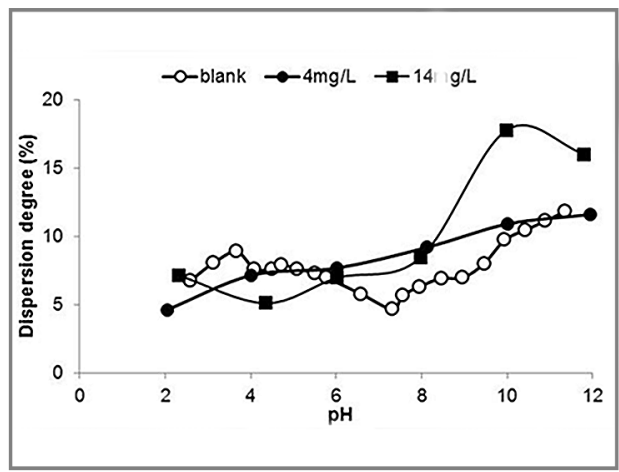

Dispersogen LFS dosed at the concentration $14 \mathrm{mg} / \mathrm{L}$ caused increase in the dispersion degree. The re-

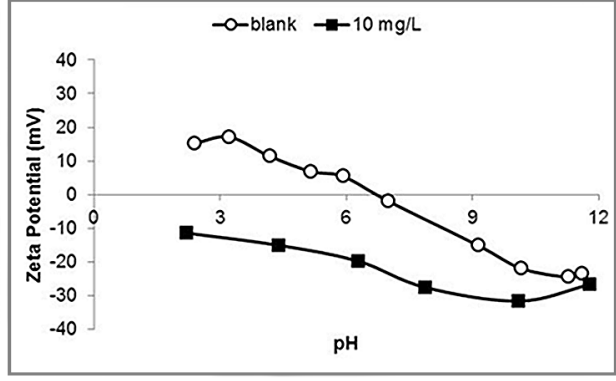

potential to more negative values, but the effects significant at $\mathrm{pH} 10$.

Results of dispersion degree and zeta potential determinations in the

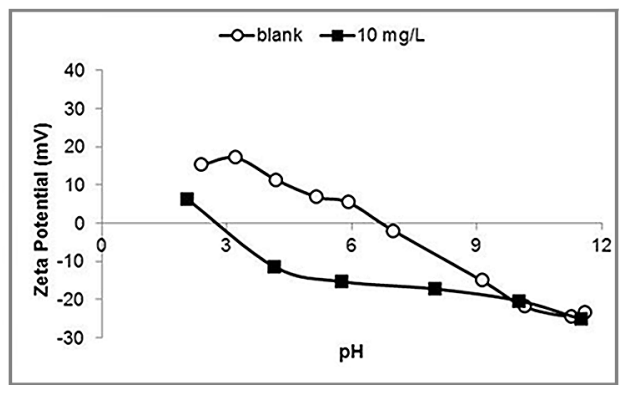

the relevant issue is that at $\mathrm{pH} 10$, the reagent does not significantly affect either the dispersion degree or the zeta potential. The IEP was shifted from 6.7 to 5.6.

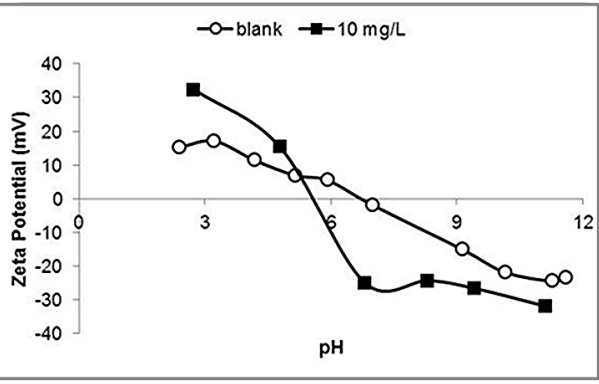

potential. The IEP was shifted from 6.7 to 5.6 .

Results of dispersion degree and

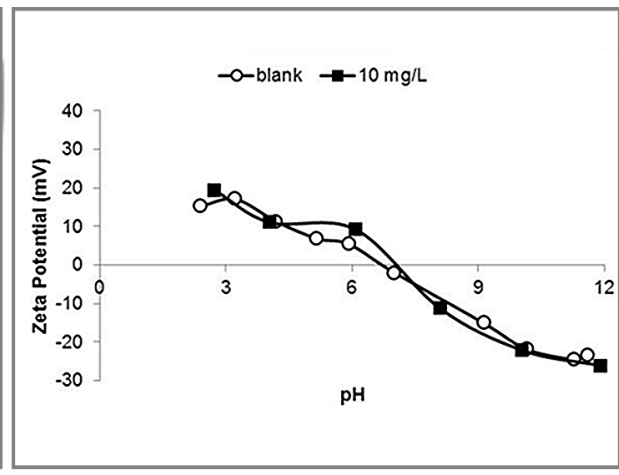

agent did not affect the zeta potential.

Results of dispersion degree and zeta potential determinations in the
Figure 7

Dispersion degree (left) and zeta potential (right) of hematite in the presence of sodium silicate R-2252.

presence of sodium silicate R-3342 are illustrated in Figure 8.

Figure 8

Dispersion degree (left)

and zeta potential (right) of hematite in the presence of sodium silicate R-3342.

Results of dispersion degree and zeta potential determinations in the presence of Dismulgan V3377 are illustrated in Figure 9.

Figure 9

Dispersion degree (left) and zeta potential (right) of hematite in the presence of Dismulgan V3377.

zeta potential determinations in the presence of Dispersogen LFS are illustrated in Figure 10.

Figure 10

Dispersion degree (left) and zeta potential (right) of hematite in the presence of Dispersogen LFS.

presence of Polymax T10 are illustrated in Figure 11. 
Figure 11

Dispersion degree (left) and zeta potential (right) of hematite in the presence of Polymax T10.

Polymax T10 dosed at both concentrations caused increase in the dispersion degree. The effect of zeta

Figure 12

Dispersion degree of hematite in the presence of Dispersol 589.

Dispersol 589, dosed at both concentrations, significantly enhanced the dispersion. The effect of this acrylate

Figure 13

Dispersion degree (left) and zeta potential (right) of hematite in the presence of Depramin 158.

The effect of Depramin 158 was similar to that of Dispersol 589, significant

\section{Conclusions}

The natural organic polymers dextrin, FloatanM3 (tannin), and Depramin 158 (carboxymethylcellulose) increase the dispersion degree of hematite in the alkaline $\mathrm{pH}$ range. A correlation is observed between the dispersion degree and the increase in the negative value of zeta potential. Isoelectric points of hematite were not observed in the presence of these reagents.

The synthetic organic polymers

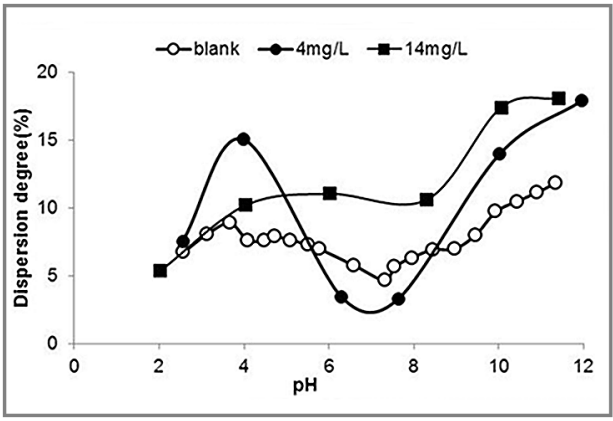

potential at $\mathrm{pH} 10$ was not significant. The IEP was shifted from 6.7 to 5.6.

Results of dispersion degree and

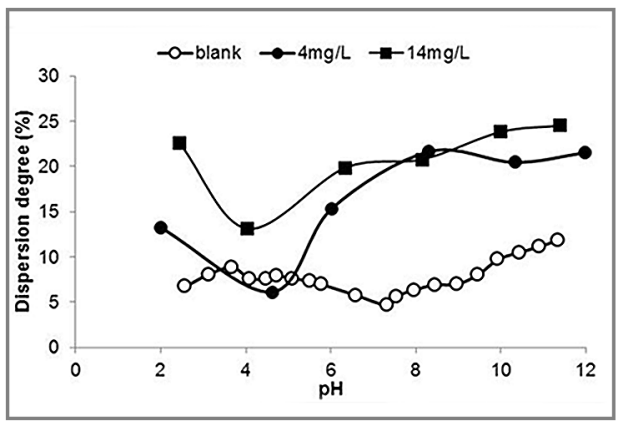

polymer on the zeta potential was negligible.

Results of dispersion degree and

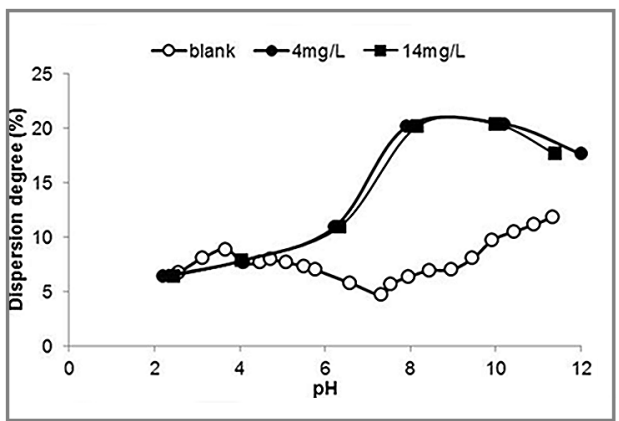

increase in the dispersion degree and negligible effect on the zeta potential.

Dismulgan V3377, Dispersogen LSF, Polymax T10, and Dispersol 589 did not significantly affect the zeta potential. Nevertheless Polymax T10 and Dispersol 589 at both concentrations and Dispersogen LSF at the higher concentration $14 \mathrm{mg} / \mathrm{L}$ enhance the dispersion of hematite particles.

The three types of sodium silicate utilized, irrespectively of the $\mathrm{SiO}_{2} / \mathrm{Na}_{2} \mathrm{O}$ ratio, at pH 10, did not significantly im-

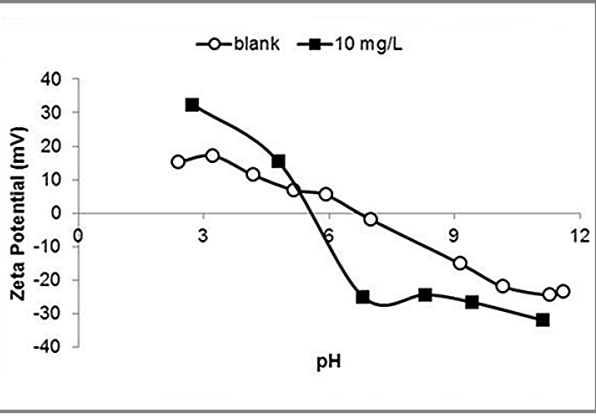

zeta potential determinations in the presence of Dispersol 589 are illustrated in Figure 12

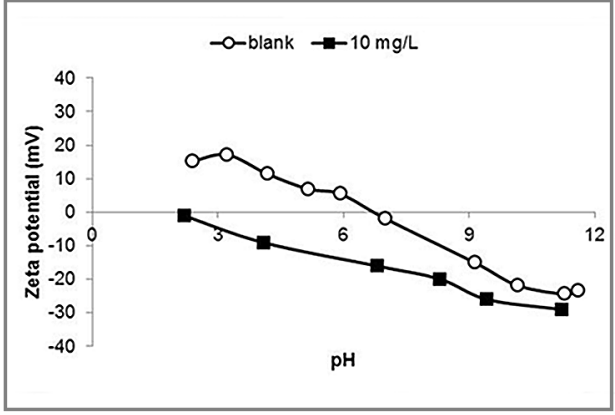

zeta potential determinations in the presence of Depramin 158 are illustrated in Figure 13.

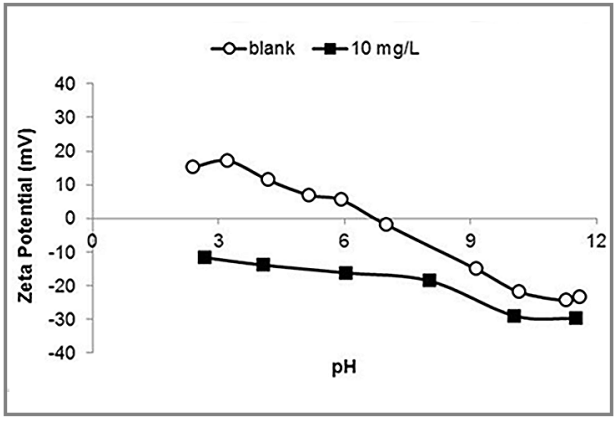

pact either the dispersion degree or the zeta potential. In the acidic and mildly alkaline $\mathrm{pH}$ range the effect was to shift the zeta potential curve towards negative values, preventing the occurrence of isoelectric points.

Citric acid enhanced the dispersion at $\mathrm{pH} 10$, despite not affecting the zeta potential at this $\mathrm{pH}$. Considering the full $\mathrm{pH}$ range, isoelectric point was not observed in the presence of this reagent.

\section{Acknowledgements}

The authors acknowledge the support of PROEX CAPES, CNPq, and FAPEMIG. 


\section{References}

CARLSON, J. J. Review of PZC and IEP for Iron Ores. Mineral Processing and Extractive Metallurgy. (Chemistry-Surfactants Series). New York: Marcel Dekker, 2010. v.37 p.407-447.

FERREIRA, E. E. Iron ore slimes: aggregation/dispersion and rheology. Belo Horizonte: Escola de Engenharia, Universidade Federal de Minas Gerais, 2002. 190p. (Doctor Thesis Engenharia Metalúrgica e de Minas - In Portuguese).

GALÉRY, R. Influence of the dispersion state on the floatability of the system willemite/dolomite. Belo Horizonte: Escola de Engenharia, Universidade Federal de Minas Gerais, 1985. 92p. (Master Thesis Engenharia Metalúrgica e de Minas - In Portuguese).

LIMA, N. P., PERES, A. E. C., MARQUES. Effect of slimes on iron ores flotation. International Journal of Mining Engineering and Mineral Processing, v.1, n.2, 2012, p. 43-46.

MARQUES, M. L. S. Iron ores behavior in the concentration via flotation in the presence of slimes. Belo Horizonte: Escola de Engenharia, Universidade Federal de Minas Gerais, 2013. 88p. (Master Thesis Engenharia Metalúrgica, Materiais e de Minas - In Portuguese).

SILVA, J. P. P., BALTAR, C. A. M., GONZAGA, R. S. G., PERES, A. E. C., LEITE, J. Y. P. Identification of sodium silicate species used as flotation depressants. Minerals \& Metallurgical Processing, v. 29, n. 4, p. 207-210, 2012.

VIEIRA, M. G., PERES, A. E. C. Effect of rheology and dispersion degree on the regrinding of an iron ore. Journal of Materials Research and Technology, 2, n.4, 2013, p. 332-338.

Received: 13 May 2014 - Accepted: 29 August 2014. 